\title{
Effect of heat treatment on proportion of duplex fiber texture of aluminium magnesium silicon alloy
}

\begin{abstract}
In the present study, an attempt has been made to understand the texture evolution of Aluminium alloy 6082-T6 after different aging heat treatment process. Effects of heat treatment in controlling the variation and domination of one fiber texture over the other in a duplex fiber texture have been observed. Texture studies were carried out with ND direction parallel to direction of extrusion. Solutionised and aged samples have shown the variations in volume fraction of $\langle 100\rangle$ and $<111>$ fibre due to effect of re-crystallization and precipitation. The presence of clusters of solutes and $\beta^{\prime \prime}$ precipitates alters the proportion of volume fraction of $\langle 100>$ and $\langle 111>$ duplex fibers. Peak aged samples showed significant strengthening of $\langle 100\rangle$ fiber as compared to solutionised and aged samples.
\end{abstract}

Keywords: texture, aluminum alloy 6082, heat treatment, volume fraction of fibers
Volume I Issue 2 - 2017

\author{
Manoj Chopkar, Shailesh Tiwari \\ Department of Metallurgical Engineering, National Institute of \\ Technology, India
}

Correspondence: Manoj Chopkar, Department of Metallurgical Engineering, National Institute of Technology, India, Emailmchopkar.met@nitrr.ac.in

Received: July 24, 2017 | Published: August 21, 2017

\section{Introduction}

The strength-to-weight ratio offered by AA6XXX alloys and their enhanced mechanical properties have become crucial criteria for their use in light weight military vehicles, rockets, missiles, aircrafts, and cars, used for both defence and civil purpose. ${ }^{1}$ Heat treatment changes the microstructure and mechanical properties of material and it also contributes to important effects on evolution of re-crystallization and deformation textures. The alloys AA6082-T6 is high strength $\mathrm{Al}-\mathrm{Mg}-\mathrm{Si}$ alloys that contain manganese to increase ductility and toughness. ${ }^{2}$ Cuniberti et al. ${ }^{3}$ have reported that, artificial aging of $\mathrm{Al}-\mathrm{Mg}-\mathrm{Si}$ alloy for $30 \mathrm{~min}$ at $180^{\circ} \mathrm{C}$ after solution treatment resulted in a significant increase in yield strength and loss of ductility, due to the rapid precipitation of the $\beta^{\prime \prime}$ intermediate phase. ${ }^{3}$ The $\beta^{\prime \prime}$ precipitates have fine needle type morphology, with the major axis in the $\langle 100\rangle$ directions of the aluminum matrix. ${ }^{3}$ The $\beta^{\prime \prime}$ phase has a composition of $\mathrm{Mg}_{5} \mathrm{Si}_{6}$ and has monoclinic $\mathrm{C}$-centred structure and is fully coherent in $\langle 100\rangle$ direction. ${ }^{4}$ The texture of an extruded face centred cubic material is of $\langle 100\rangle$ and $\langle 111\rangle$ duplex fibre texture parallel to the direction of extrusion. ${ }^{5}$ The study of dependence of the proportion of $<111>$ and $<100>$ fibre on heat treatment by Demakov et al. ${ }^{6}$ exhibited changes in volume fraction of fibres radially and with annealing temperature in copper wires. ${ }^{6}$ Gerber et al. ${ }^{7}$ have also shown the significant variation in proportion of cube texture in cold rolled copper above annealing temperature of $130^{\circ} \mathrm{C} .^{7}$

The deformation texture in FCC metals and alloys is strongly dependent on the stacking fault energy. ${ }^{8}$ All Face centred cubic (FCC) material under axisymmetric deformation like wire drawing and extrusion produce duplex fiber texture of $<111>$ and $<100>$ parallel to the direction of drawing or extrusion. The proportion of volume fraction of $<111>$ as compared to $<100\rangle$ varies depending on the mode of deformation (drawing or extrusion) and also on the stacking fault energy of the material. ${ }^{9}$ Waryoba et al. ${ }^{10}$ studied the effect of annealing temperature on the texture of OFHC copper wire. The strong $<111>$ fiber first decreases with annealing temperature but then increases again. ${ }^{10}$

However, there is no literature available on effect of ageing on the duplex fiber texture of high stacking fault energy face centered cubic materials. Therefore, in the present study an attempt has been made to understand the texture evolution of Aluminium alloy 6082-T6 after different ageing process. This study can be utilized to control the predeformation initial texture of aluminum alloy 6082-T6.

\section{Material and methodology}

The Aluminum Alloy 6082-T6 in extruded form was procured and cylindrical samples were prepared with $10 \mathrm{~mm}$ diameter and $5 \mathrm{~mm}$ height. Table 1 shows the composition of the alloy. The AA6082T6 was in the form of hot extruded bar of $25.4 \mathrm{~mm}$ diameter and cylindrical samples were cut with axis parallel to the direction of extrusion. Texture studies were done on face normal to the direction of extrusion.

These samples were solutionised at $560^{\circ} \mathrm{C}$ for two hours and water quenched. Some of the solutionsed samples were aged at $170^{\circ} \mathrm{C}$ for four hours and some were aged at same temperature for 16 hours. Texture studies were done using Rigaku Ultima IV four circle goniometer diffractometer and analysis done using ResMatTexTools. All texture studies were done with the ND direction parallel to the direction of extrusion.

Table I Chemical composition of AA 6082

\begin{tabular}{lccccccc}
\hline Elements & $\mathrm{Mg}$ & $\mathrm{Si}$ & $\mathrm{Cu}$ & $\mathrm{Fe}$ & $\mathrm{Mn}$ & $\mathrm{Cr}$ & $\mathrm{Al}$ \\
\hline Wt $\%$ & 1.2 & 0.8 & 0.1 & 0.2 & 0.5 & 0.17 & $\mathrm{Bal}$
\end{tabular}

\section{Results and discussion}

The heat treatment of precipitation harden able AA6082 alloy affects the volume fraction of $<111>$ and $<100>$ duplex fibre through planarity of slip and recrystallization due to combined effect of stacking fault energy, deformation stage, ageing condition and precipitation state. An attempt has been made to explain the possible reasons for the variations of ratio of duplex fiber due to of heat treatment and presence of types of precipitates, in the following section.

The volume fraction of various fibers observed in extruded, solutionised and aged samples has been listed in Table 2. The same has been calculated using the Resmat-Textool. 


\section{Texture of the initial material}

The texture of an extruded AA6082 is typical round extruded face centred cubic texture of $<111>$ and $<100>$ duplex fibre texture parallel to the direction of extrusion. It had strong $<100>$ fiber with comparable $<111>$ fiber (Figure 1). The volume fraction of $<100>$ was $38.24 \%$ as compared to $<111>$ at $31.57 \%$. The maximum intensity was at 11.0 . The $\{111\}$ pole figure showed strong cube texture with maximum intensity of 8.1units (Figure 1). The contour lines in the IPF show the frequency with which various $\langle\mathrm{uvw}\rangle$ directions in the crystal coincide with the normal direction which is the direction of the extrusion in current study. In FCC materials, axisymmetric deformation like extrusion has higher order of symmetry and produces $<100>$ and $<111>$ fiber texture. During deformation the plastic strain is accommodated by dislocation motion and by realignment of grains.

Table 2 Volume fraction (\%) of 100,110 and III fibers in all four samples

\begin{tabular}{|c|c|c|c|c|c|}
\hline Volume fraction (\%) & 100 Fiber & I I I Fiber & I I 0 Fiber & Random fiber & $100 / 111$ \\
\hline & & & & & Ratio \\
\hline 6082 EXTRUDED T6 & 38.24 & 31.37 & 8.9 & 21.29 & 1.211277 \\
\hline 6082 SOLUTIONISED & 28.72 & 29.72 & 11.38 & 30.2 & 0.966353 \\
\hline 6082 AGE 4HR & 25.15 & 28.23 & 11.38 & 35.24 & 0.890896 \\
\hline 6082 AGE I 6HR & 36.24 & 28.83 & 10.21 & 24.7 & I. 257024 \\
\hline
\end{tabular}

(a)

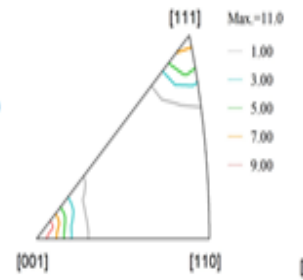

(b)
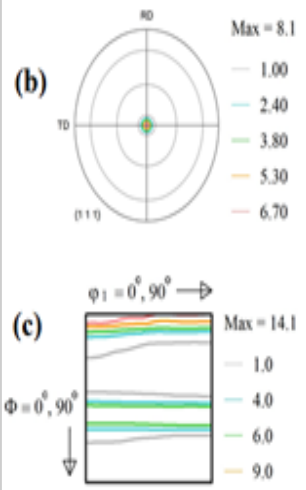

Extruded
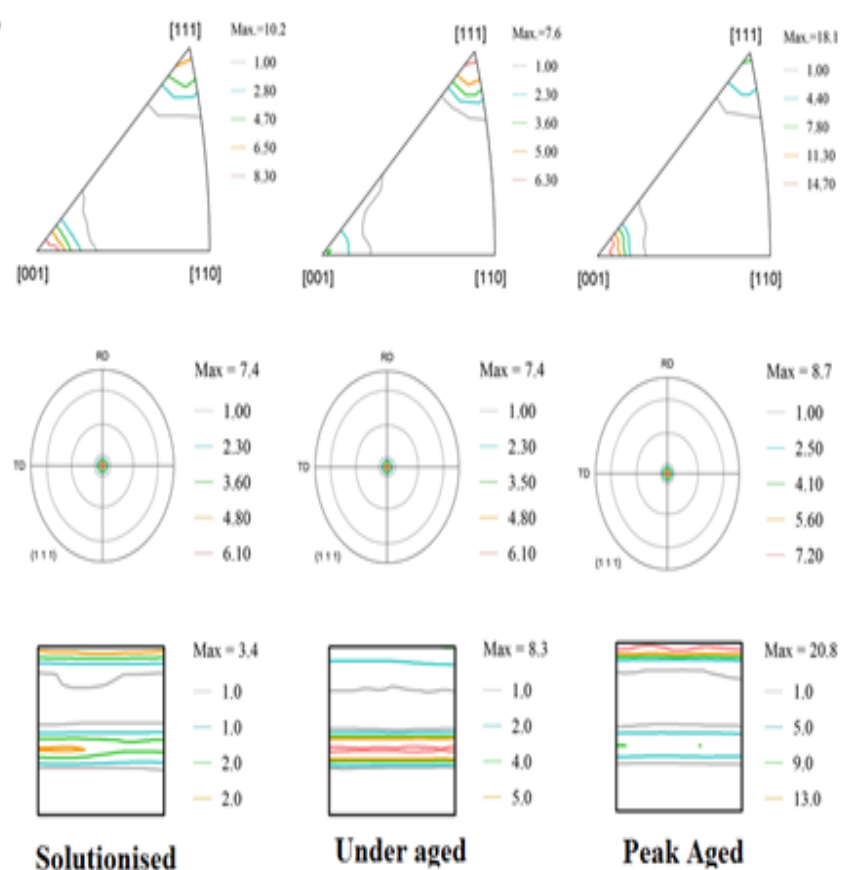

Figure I (a) ND-Inverse Pole Figure, (b) II I Pole Figure and (c) ODF $\varphi_{2}=45^{\circ}$ section of extruded, Solutionised, $4 \mathrm{hr}$ aged and I6 hr aged AA6082.

\section{Texture of solutionised sample}

Samples were heated at a temperature of $560^{\circ} \mathrm{C}$ for two hours and water quenched. Immediately after quenching, solute atoms are randomly distributed in solid solution in the Aluminium matrix. The solutionised samples showed slight drop in the volume fraction of $<111>$ fiber while the drop in $<100>$ was significant. The volume fraction of $<100>$ dropped from $38.24 \%$ to $28.72 \%$ whereas the $<110>$ fiber fraction increased from $8.9 \%$ to $11.38 \%$ (Figure 2). The $\{111\}$ pole figure showed strong cube texture with max intensity of 7.4 units.

\section{Texture of aged samples}

Solutionised samples were aged at $170^{\circ} \mathrm{C}$ for 4 hours and 16 hours to get variation in the extent of precipitation. The texture of the sample aged for 4 hours displayed a further reduction of fraction of $<100>$ fiber from $28.72 \%$ to $25.15 \%$. The volume fraction of $<111>$ further dropped marginally to $28.23 \%$. The $\{111\}$ pole figure showed strong cube texture with 7.4 maximum intensity. The observed change may be due to the formation of individual clusters of Silicon and Magnesium and also clusters containing both of random sizes and shapes. These clusters do not favor any particular orientation hence no significant change in any orientation is observed.

The texture of the sample aged for 16 hours displayed a recovery of fraction of $<100>$ fiber from $28.72 \%$ back to the range of the extruded texture i.e. at $36.24 \%$. The volume fraction of $<111>$ further dropped marginally to $28.83 \%$. The $\{111\}$ pole figure showed strong cube texture with 8.7 maximum intensity. The increase in the $<100>$ fiber fraction is due to the increased volume of elongated $\beta^{\prime \prime}$ precipitates with prolonged ageing. Similar observations of $\beta^{\prime \prime}$ precipitates affecting the $\langle 100>$ fiber favorably during annealing has been made by Demakov et $a .^{6}$ \& Wayroba et al. ${ }^{10}$ The ultrathin and elongated 
$\beta^{\prime \prime}$ precipitated favor strengthening of $<100>$ fiber as their axis is coherent to only 100 directions. $^{?}$

The orientation distribution plot shows the variation of $<100>$ fiber intensity at $\Phi=0^{\circ}$ and $\Phi_{2}=45^{\circ} \mathrm{C}$ (Figure 3). The intensity of the $<100>$ fiber decreases marginally on solutionising and further on under ageing while it significantly increases manifold for 16 hours peak aged sample.

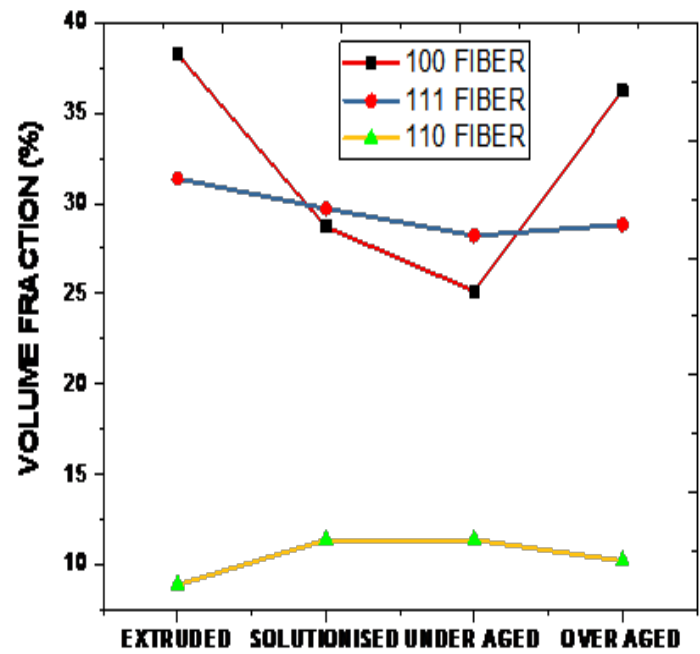

Figure 2 Volume fraction of $\langle\mid 00\rangle,\langle|| \mid\rangle$ and $\langle|| 0\rangle$ fibers for different heat treated AA6082.

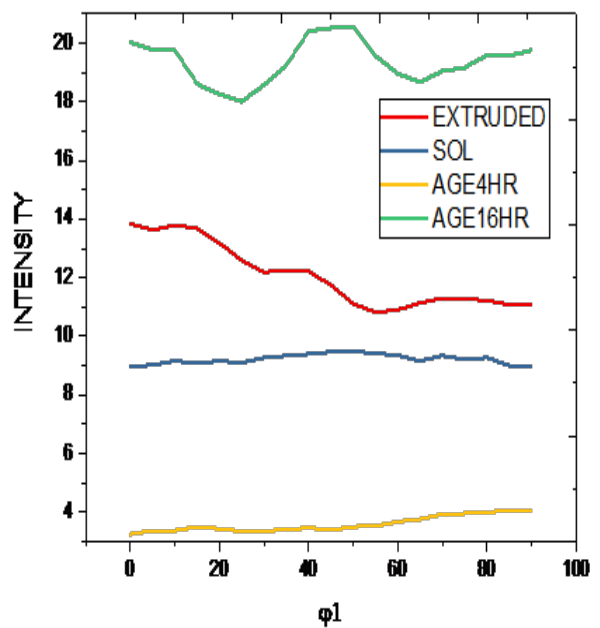

Figure 3 Intensity of $\langle 100\rangle$ fiber at $\Phi=0 \circ$ and $\Phi_{2}=45^{\circ}$ for sample at all four conditions.

\section{Conclusion}

The volume fraction of $<100>$ fiber of extruded AA 6082 decreases significantly $(24.89 \%$ of original fraction) on solutionising while the fraction of $<111>$ reduces marginally $(5.86 \%)$. This is due to secondary recrystallization/grain growth and dissolution of $\beta^{\prime \prime} \mathrm{Mg}_{5} \mathrm{Si}_{6}$ precipitates which favor $<111>$ fiber formation. On Ageing, initially the fraction of all fiber change marginally. On further ageing to 16 hours the fraction of $<100>$ fiber increases significantly to $36.24 \%$ due to intensive $\beta^{\prime \prime}$ precipitation favoring only $<100>$ fiber formation. The presence of $\beta^{\prime \prime}$ precipitates alters the proportion of volume fraction of $<100>$ and $<111>$ duplex fibers and can be utilized favorably in the evolution of deformation texture of materials by controlling the initial texture before deformation. $<100>$ dominated over $<111>$ for initial deformed sample and for sample aged for 16 hours, whereas $<111>$ dominated marginally for solutionised and four hour aged sample. Heat treatment can be used to control the fraction and domination of one fiber texture over the other in a duplex fiber texture.

\section{Acknowledgements}

The authors would like to express sincere thanks to Dr. Satyam Suwas and N-RCM of Indian Institute of Science, Bangalore for their continuous help and suggestions. This work was supported by the Science and Engineering Research Board, India under grant numbers SB/FTP/ETA-122, 2013. Special thanks to Mirtunjay Kumar and Amit Singh for assistance in experiment and analysis.

\section{Conflict of interest}

The author declares no conflict of interest.

\section{References}

1. Prantik Mukhopadhyay. Alloy designation, processing, and use of AA6XXX series aluminium alloys. ISRN Metallurgy. 2012;2012:15.

2. Moreira PMGP, Santos T, Tavares SMO, et al. Mechanical and metallurgical characterization of friction stir welding joints of AA6061-T6 with AA6082-T6. Materials and Design. 2009;30(1):180-187.

3. Cuniberti A, Tolley A, Riglos MC, et al. Influence of natural aging on the precipitation hardening of an AlMgSi alloy. Materials Science and Engineering: A. 2010;527(20):5307-5311.

4. Andersen SJ, Zandbergen HW, Jansen J, et al. The crystal structure of the $\beta^{\prime \prime}$ phase in Al-Mg-Si alloys. Acta Materialia. 1998;46(9):3283-3298.

5. McHargue CJ, Jetter LK, Ogle JC. Preferred orientation in extruded aluminum rod. Transactions of the American institute of mining and metallurgical engineers. 1959;215(5):831-837.

6. Demakov SL, Loginov YN, Illarionov AG, et al. Effect of annealing temperature on the texture of copper wire. The Physics of Metals and Metallography. 2012;113(7):681-686.

7. Gerber P, Tarasiuk J, Chauveau T, et al. A quantitative analysis of the evolution of texture and stored energy during annealing of cold rolled copper. Acta materialia. 2003;51(20):6359-6371.

8. Suwas S, Toth LS, Fundenberger JJ, et al. Texture evolution in FCC metals during Equal Channel Angular Extrusion (ECAE) as a function of stacking fault energy. In Solid State Phenomena. 2005;105:345-350.

9. English AT, Chin GY. On the variation of wire texture with stacking fault energy in fcc metals and alloys. Acta metallurgica. 1965;13(9):10131016.

10. Waryoba DR, Kalu PN. Deformation and recrystallization texture of heavily drawn OFHC copper. In Materials Science Forum. 2005;495:877-882. 